Jean-Pierre Danthine · Xiangrong Jin

\title{
Intangible capital, corporate valuation and asset pricing
}

Received: 15 January 2006 / Revised: 12 October 2006 / Published online: 19 January 2007 (c) Springer-Verlag 2007

\begin{abstract}
Recent studies have found unmeasured intangible capital to be large and important. In this paper we observe that by nature intangible capital is also very different from physical capital. We find it plausible to argue that the accumulation process for intangible capital differs significantly from the process by which physical capital accumulates. We study the implications of this hypothesis for rational firm valuation and asset pricing using a two-sector general equilibrium model. Our main finding is that the properties of firm valuation and stock prices are very dependent on the assumed accumulation process for intangible capital. If one entertains the possibility that intangible investments translates into capital stochastically, we find that plausible levels of macroeconomic volatility are compatible with highly variable corporate valuations, $P / E$ ratios and stock returns.
\end{abstract}

Keywords Intangible capital · Corporate valuation · Stock return volatility

JEL Classification Numbers D24 · D50 - G12

We thank Ellen McGrattan, Edward Prescott, Rene Stulz and an anonymous referee for their help-
ful comments as well as workshop participants at FAME, the 5th Conference of the Swiss Society
for Financial Market Research, the European Central Bank, Columbia Business School Finance
Free Lunch and the University of Zürich. This research has benefited from financial support from,
the National Center for Competence in Research "Financial Valuation and Risk Management".
The National Centers of Competence in Research are managed by the Swiss National Science
Foundation on behalf of the Federal Authorities.

J.-P. Danthine $(\bowtie)$

Swiss Finance Institute, University of Lausanne, Lausanne, Switzerland

CEPR, London, UK

E-mail: jdanthine@unil.ch

$X$. Jin

Hong Kong Monetary Authority, Hong Kong, China 


\section{Introduction}

Recent research has emphasized important implications of the fact that the productive sector appears to rely heavily and possibly increasingly on what is usually called intangible capital, as opposed to the traditional "brick and mortar" methods of production. Hall $(2000,2001)$ argues that e-capital (a body of technical and organizational know-how) provides the dominant explanation for the upsurge in corporations' valuations in the 1990s. Corrado et al. (2005) estimate that, by about the mid-1990s, business investment in intangible capital was as large as business investment in traditional, tangible capital. McGrattan and Prescott (2006) argue that incorporating unmeasured investment is necessary to account for the boom in hours worked in the US in the 1990s. The latter authors estimate that unmeasured intangible investment in the business sector rose from $3 \%$ of GDP prior to 1990 to over $8 \%$ of GDP in the 1990s with the consequence that labor productivity growth over the 1993-2000 period was underestimated by $1.2 \%$ per year. In previous work (McGrattan and Prescott 2005), the same authors, building on the assumption that the equilibrium after-tax returns on tangible and intangible capital should be roughly equal, had estimated the value of the stock of unmeasured intangible capital (in the US corporate sector) to exceed 60\% of GDP with a confidence interval ranging from 0.5 to $1.0 \mathrm{GDP}$.

Intangible capital is the result of investments in developing and launching new products, marketing, R\&D and software expenditures, investments in firms' organizational capital as well as investments in human capital through training, schooling and on-the-job learning. ${ }^{1}$ These are investments to the extent that they imply a decrease in current productivity. Human capital investments are part of intangible capital to the extent that they are firm specific and not appropriated by workers. Some investments in intangible capital are appropriable; they are then often protected by copyrights and patents. Patented ideas are probably a small fraction of total intangible capital, however (Zambon 2003). Firm specific knowledge, ideas and human capital can to a large extent be considered as non-appropriable. While intangible capital is sometimes properly accounted for (especially under the heading of goodwill), the bulk of it is treated as operating expenses. It is only very recently that the Financial Accounting Standards Board (FASB) has recognized that intangible assets have a legitimate place in the accounts. The Financial Times of March 5, 2002 reports that the FASB "is working on rules that will require US companies to disclose, for the first time, information regarding intangible assets.... It is no secret that the conventional balance sheet gives investors very little useful information about intangibles. ... Investment in intangibles is treated as an expense against revenue. ... Advertising, marketing, training, etc. are currently under the heading of selling, general and administrative expenses'."

This paper starts with the observation that the very distinct nature of intangible capital makes it plausible that the process by which it is accumulated may

${ }^{1}$ To these standard items, McGrattan and Prescott (2006) add "sweat investment": uncompensated hours made with the expectation of realizing capital gains when the business goes public or is sold. They report that "data from the Current Population Survey of the US Department of Labor show a shift of labor into IT-related and managerial occupations with greater opportunities for business owners to make capital gains on expensed and sweat investment." They also stress that "the National Science Foundation on R\&D investment shows that R\&D relative to GDP grew by $30 \%$ between 1994 and 2000." 
not be a perfect replica of the accumulation process for physical capital. This is in contrast with what the literature has assumed so far. While physical capital is typically viewed as accumulated one for one with investment expenses, we are rather attracted to the view that intangible capital is the result of a process subject to rare potential breakthroughs leading to rapid increases in its value, in line with what is commonly assumed in the R\&D literature. The Mexican brewer, Corona, progressed from a relatively unknown maker of beer to a fashion success. In this case, the build-up in the company's value is the result of deft advertising expenses that should not be considered as expenses but as investments that paid off one day, in a quite unpredictable and extraordinary way. In the case of Google, nothing else than its enormous intangible capital could explain its rapid buildup from scratch in 1998 to its current US \$117 billion market capitalization. Such a fast accumulation of intangible capital does not seem to conform to a standard physical capital investment process, but rather to a process made of surprises, innovations and breakthroughs.

Our objective is to illustrate the implications of this hypothesis. We conjecture that assuming stochastic intangible capital accumulation may shed light on the puzzling (from the viewpoint of existing theories) volatility of observed financial indicators. Our experiment consists in embedding a stochastic intangible capital accumulation process in a calibrated two-sector general equilibrium model and checking whether the hypothesis can be rejected by, or on the contrary finds support in, the resulting characteristics of the economy evaluated at three levels: macroeconomic volatility, corporate valuation and asset returns.

In our economy, traditional firms use a standard technology to produce their output while 'new economy' firms rely crucially on intangible assets. Intangible capital is the result of investing in R\&D-like activities and is firm-specific. It is not traded and not appropriable although it depreciates through time. A major simplification in our analysis is that we abstract from the growth process.

Our main findings are as follows. At the macroeconomic level, we find that the assumption of a stochastic accumulation process for intangible capital does increase macroeconomic volatility by about $25 \%$, thus enabling the baseline RBC model to come closer to reproducing observed GDP volatility. This increased volatility remains substantially unmeasured, however. The mis-measured GDP volatility increases by as little as $6 \%$ in one of our main scenarios. Despite this very modest macroeconomic impact, the consequences of assuming a stochastic accumulation process for intangible capital are very significant at the financial level. Aggregate equity returns are significantly more volatile (more than twice as much) under the stochastic accumulation assumption; the volatility of the market capitalization to GDP ratio doubles and the (percent) volatility of the Price/Earnings ratio for the aggregate market index increases by almost $70 \%$. On these fronts, the property of an otherwise run-of-the mill Real Business Cycle model falls almost perfectly in line with the observations made on the S\&P500 index over the last 60 years. We view these results as highly significant given the substantial difficulties in accounting for important financial observations (e.g., Shiller 1981; Mehra and Prescott 1985; Mehra 1998). In our view, these results warrant going beyond the exploratory nature of the present inquiry in order to accumulate data and facts on the exact process by which intangible investment translates into capital. The resolution of some outstanding pricing puzzles may be the ultimate reward. 
The rest of the paper is organized as follows. The model set up is presented in Sect. 2. Section 3 discusses the equilibrium and the adopted solution method. Section 4 summarizes the calibration exercise. Our results are collected in Sect. 5 and a detailed sensitivity analysis is performed in Sect. 6. Section 7 concludes. The detailed solution method is provided in an Appendix.

\section{The economy}

The economy of this paper features two types of firms and a household deriving utility from leisure and the consumption of the two types of goods being produced. The two firm types not only produce different goods, but, more significantly, they are endowed with different technologies. Type 1 firms are traditional in the sense of producing goods out of a combination of standard inputs: labor and physical capital. Type 2 firms, by contrast, combine intangible capital with physical capital and labor to produce their output. The representative household owns the two firms and is entitled to all dividends (a term we use generically for distributions as our model does not distinguish between dividends and share buybacks). ${ }^{2}$

\subsection{Household sector}

The representative household is an infinitely-lived worker and shareholder. At each date, she supplies labor to the two sectors of the economy. She derives utility from leisure and the consumption of both goods. Consumption is financed out of her labor income and dividends from the two existing firms. She solves the following optimization problem:

$$
\max _{\left\{C_{1, t}, C_{2, t}, L_{t}, Z_{1, t+1}, Z_{2, t+1}\right\}_{t=0}^{\infty}} E_{0} \sum_{t=0}^{\infty} \beta^{t} U\left(C_{1, t}, C_{2, t}, L_{t}\right)
$$

subject to

$$
\begin{aligned}
& C_{1, t}+P_{t} C_{2, t}+Q_{1, t} Z_{1, t+1}+Q_{2, t} Z_{2, t+1} \\
& \quad \leq\left(D_{1, t}+Q_{1, t}\right) Z_{1, t}+\left(D_{2, t}+Q_{2, t}\right) Z_{2, t}+W_{t} L_{1, t}+W_{t} L_{2, t}, \quad \forall t,
\end{aligned}
$$

where $E_{t}$ is the expectation operator conditional on the available information up to time $t, \beta$ the subjective discount rate. $C_{i, t}$ is the consumption of firm $i$ 's good at time $t$ for $i=1,2$. The traditional sector's product is good 1, the 'new economy' sector's product is labelled good 2. The price of consumption good 1 is taken as the numeraire; $P_{t}$ henceforth is the spot price of consumption good 2 in terms of good 1 at time $t$. $D_{i, t}$ stands for distributions or dividends from firm $i$ paid out at time $t$, $i=1,2$. $Z_{i, t+1}$ is the number of shares of firm $i$ held by the consumer at the end of period $t, i=1,2$. Each firm has one perfectly divisible share outstanding. The period $t$ (ex-dividend) price of equity is $Q_{i, t}, i=1,2$. $W_{t}$ is the wage rate prevailing at time $t$; it is common to both sectors as labor moves freely across sectors.

${ }^{2}$ By contrast, in the two sector economy of McGrattan and Prescott (2006), one sector produces the consumption good while the other produces intangible capital which serves as a factor of production to both sectors. 
$L_{i, t}, i=1,2$ is the labor input in sector $i$ with $L_{t}=L_{1, t}+L_{2, t}$ representing total hours worked at time $t$. Thus, $1-L_{t}$ is the leisure time of the household at each date $t$.

We assume that preferences are additively separable across leisure and consumption of goods while non-additively separable across goods. The functional form of $U(\cdot, \cdot, \cdot)$ is assumed to be:

$$
U\left(C_{1, t}, C_{2, t}, L_{t}\right)=\left(C_{1, t}^{\gamma}+b C_{2, t}^{\gamma}\right)^{1 / \gamma}+\frac{s}{v}\left(1-L_{t}\right)^{\nu},
$$

where $b$ determines the relative importance and $\gamma$ the elasticity of substitution between the two goods while $s$ and $v$ are parameters determining working time and the labor supply elasticity.

Our working hypothesis is that the two consumption goods are heterogeneous enough so that the amount spent on the 'new economy' sector's good, say, software or internet services, does not affect the marginal utility of consuming the other, say, food.

The FOC's for the above optimization problem are:

$$
\begin{gathered}
P_{t}=\frac{U_{2, t}}{U_{1, t}}=b\left(\frac{C_{2, t}}{C_{1, t}}\right)^{\gamma-1} \\
s\left(1-L_{t}\right)^{\nu-1} W_{t}=\left(C_{1, t}^{\gamma}+b C_{2, t}^{\gamma}\right)^{\frac{1}{\gamma}-1} C_{1, t}^{\gamma-1} \\
U_{1}\left(C_{1, t}, C_{2, t}, L_{t}\right) Q_{i, t}=\beta E_{t} U_{1}\left(C_{1, t+1}, C_{2, t+1}, L_{t}\right)\left(Q_{i, t+1}+D_{i, t+1}\right), \quad i=1,2
\end{gathered}
$$

The third equation can be solved forward for

$Q_{i, t}=E_{t} \sum_{j=1}^{J} \beta^{j} \frac{U_{1}\left(C_{1, t+j}, C_{2, t+j}, L_{t+j}\right)}{U_{1}\left(C_{1, t}, C_{2, t}, L_{t}\right)} D_{i, t+j} \equiv E_{t} \sum_{j=1}^{J} \rho_{t}^{j} D_{i, t+j}, \quad i=1,2$

where $\rho_{t}^{j}$ represents the appropriate stochastic discount factor for a $j$-period ahead cash flow at time $t$.

\subsection{Traditional sector}

The representative traditional firm's production function is

$$
Y_{1, t}=A_{t} K_{1, t}^{\alpha_{1}} L_{1, t}^{1-\alpha_{1}},
$$

where $K_{1, t}$ is the physical capital available at time $t$ and $L_{1, t}$ is the labor input in the traditional firm's production; $0<\alpha_{1}<1 ; A_{t}$ is a global productivity shock common to both firms and assumed to follow:

$$
\log A_{t+1}=\psi \log A_{t}+\varepsilon_{t+1},
$$

with $0<\psi<1$ and $\varepsilon_{t}$ are i.i.d normal variates with mean 0 and variance $\sigma^{2}$.

The dynamics of the physical capital $K_{1}$ is given by a standard accumulation process:

$$
K_{1, t+1}=(1-\delta) K_{1, t}+I_{1, t},
$$

where $\delta$ is the depreciation rate and $I_{1, t}$ is the investment in physical capital at time $t$. 
Output $Y_{1}$ can be used for investment in physical capital by both sectors, $I_{1}$ and $I_{2}$, or as consumption good $1, C_{1}$. Sector 1's aggregate resource constraint thus reads

$$
C_{1, t}+I_{1, t}+I_{2, t} \leq A_{t} K_{1, t}^{\alpha_{1}} L_{1, t}^{1-\alpha_{1}} .
$$

With a competitive labor market, the wage rate equals the marginal productivity of labor:

$$
W_{1 t}=\left(1-\alpha_{1}\right) Y_{1 t} / L_{1 t} .
$$

At each date $t$, the traditional firm's dividend, is

$$
D_{1, t}=Y_{1, t}-I_{1, t}-W_{1 t} L_{1, t}=\alpha_{1} Y_{1, t}-I_{1, t} .
$$

The traditional firm selects an investment plan and labor input to maximize the expected present value of its future profit flows, conditional on its current available information set:

$$
\max _{\left\{I_{1, t+j}, L_{1, t+j}\right\}_{j=0}^{\infty}} E_{t} \sum_{j=0}^{\infty} \rho_{t}^{j} D_{1, t+j}
$$

subject to (1)-(4) and

$$
I_{1, t+j} \geq 0,1>L_{1, t+j} \geq 0, \quad \forall j \geq 0 .
$$

\section{3 "New economy" sector}

The 'New economy' firms are characterized by their reliance on intangible capital. They combine intangible capital with physical capital and labor to produce a good that is consumed as $C_{2, t}$, or serves as input to produce intangible capital $K_{I, t} . H_{t}$ is a measure of investment in intangible capital. The new economy sector's resource constraint thus reads

$$
C_{2, t}+H_{t} \leq Y_{2, t} .
$$

The representative 'new economy' firm's production function is:

$$
Y_{2, t}=A_{t} K_{I, t}^{\alpha_{I}} K_{2, t}^{\alpha_{2}} L_{2, t}^{1-\alpha_{I}-\alpha_{2}},
$$

where $K_{I, t}$ is the stock of intangible capital and $K_{2, t}$ is the stock of physical capital available for production in period $t$, and $\alpha_{I}, \alpha_{2}$ are technology parameters. $L_{2, t}$ is the labor input of the 'new economy' firm, which is the difference between total labor input and labor input in sector 1 :

$$
L_{2, t}=L_{t}-L_{1, t}, \quad \forall t,
$$

while the marginal productivity of labor in the sector is equated to the wage rate:

$$
W_{t}=\left(1-\alpha_{I}-\alpha_{2}\right) Y_{2 t} P_{t} / L_{2, t} .
$$


The dynamics of physical capital $K_{2}$ is identical to what has been assumed for physical capital in sector 1 :

$$
K_{2, t+1}=(1-\delta) K_{2, t}+I_{2, t},
$$

where $I_{2, t}$ is the investment in physical capital undertaken by sector 2 firm at time $t$. Both $I_{1}$ and $I_{2}$ are produced and sold by the traditional firm at a price of unity.

The defining characteristics of our model is in the assumed dynamics of $K_{I}$. It is specified as follows:

$$
K_{I, t+1}=(1-\kappa) K_{I, t}+\theta_{t+1} H_{t}
$$

In this process, $\kappa$ is a constant depreciation rate possibly different from the depreciation rate assumed for physical capital while $\theta$ is a variable measuring the effectiveness of intangible investments in creating operational intangible capital. ${ }^{3}$ Thus the intangible capital stock next period depends on the non-depreciated intangible capital stock, on this period intangible investment, and on the effectiveness of that investment to be known at the beginning of next period.

If $\theta$ is identical to 1 , the accumulation process for intangible capital is the same as the one usually assumed for physical capital. This is the McGrattanPrescott $(2005,2006)$ hypothesis [also adopted by Laitner and Stolyarov (2003)]. We will contrast this reference case with three alternative hypotheses where the effectiveness variable $\theta$ is stochastic. These three hypotheses define our three central scenarios:

In Scenario 1 we make the assumption that $\theta$ s are serially uncorrelated. In this case, $\theta$ is characterized by a Bernoulli distribution taking a value potentially much larger than $1\left(\theta^{h}\right)$ with a small breakthrough probability $p_{s}$, and a slightly smaller than 1 normal value $\left(\theta^{n}\right)$ with the complementary high probability $1-p_{s}$. With uncorrelated shocks, the breakthrough probability is not affected by whether a breakthrough occurred in the previous period or not. The probability transition matrix thus takes the form:

\begin{tabular}{c|cl}
\hline & $\theta_{t+1}=\theta^{h}$ & $\theta_{t+1}=\theta^{n}$ \\
\hline$\theta_{t}=\theta^{h}$ & $p_{s}$ & $1-p_{s}$ \\
$\theta_{t}=\theta^{n}$ & $p_{s}$ & $1-p_{s}$ \\
\hline
\end{tabular}

We restrict our inquiry to the context of a stationary economy. This stochastic structure is meant to capture the possibility of potential breakthroughs in technology leading to sudden increases in intangible capital, while preserving the usual linear relation between investment and capital.

In Scenario 2, $\theta$ is assumed to follow a Markov chain, incorporating the feature that new ideas arrive in "cascade". In this case, the $\theta$ s are correlated: next period's probability depends on the current state. Hypothesis 2 proposes a symmetric

\footnotetext{
${ }^{3}$ The depreciation rate, $\kappa$, could be viewed as being random, reflecting a process of "creative destruction" that would not be foreign to the idea of the present paper. As a result of some firms' technological advance, part of the intangible capital stock of other (competing) firms may well become obsolete. At this stage, we however maintain an assumption of firm homogeneity that rules out this phenomenon.
} 
Markovian structure for the transition matrix such as:

\begin{tabular}{l|ll}
\hline & $\theta_{t+1}=\theta^{h}$ & $\theta_{t+1}=\theta^{n}$ \\
\hline$\theta_{t}=\theta^{h}$ & $1-p_{s}$ & $p_{s}$ \\
$\theta_{t}=\theta^{n}$ & $p_{s}$ & $1-p_{s}$ \\
\hline
\end{tabular}

where $p_{s}$ is presumed to be small. The symmetry implies that success may be persistent. If a breakthrough has occurred at time $t$, the probability remains high that another breakthrough will be observed at $t+1$. This feature reflects clustered periods of new findings: success breads success. Here as well we restrict our investigation to a zero-average-growth context. Our stationarity assumption imposes $\theta^{h}=2-\theta^{n}$.

Scenario 3 maintains the Markovian structure for the transition matrix but removes the symmetry assumption of Scenario 2: normal times are persistent, breakthroughs are harder to sustain. Again we assume values of $\theta^{h}$ and $p_{s}$ compatible with a stationary economy. This is formalized by a transition matrix such as:

\begin{tabular}{l|ll}
\hline & $\theta_{t+1}=\theta^{h}$ & $\theta_{t+1}=\theta^{n}$ \\
\hline$\theta_{t}=\theta^{h}$ & $1-p_{s}$ & $p_{s}$ \\
$\theta_{t}=\theta^{n}$ & 0.1 & 0.9 \\
\hline
\end{tabular}

Figure 1 illustrates the time evolution of the stock of intangible capital under these alternative assumptions. In Scenario 1, intangible shocks are uncorrelated, the probability of a breakthrough is 0.1 while the breakthrough magnitude is 1.9 and the normal value of $\theta$ is 0.9 ; the stock of intangible capital is very stable with a standard deviation of about $3-4 \%$ and a range of values $\pm 12 \%$ over a 25 yearperiod. In Scenario 2, with correlated shocks and a symmetric transition probability matrix, we assume that the probability of a breakthrough given that a breakthrough has occurred this period is 0.9 and the magnitude of a breakthrough is 1.1 . The range of values taken by $K_{I}$ is broader in this case: in the absence of a technological breakthrough, intangible capital depreciates rather quickly but it can expand more substantially in a short time horizon when a cascade develops. The standard deviation of the intangible capital stock increases to $14 \%$ and the range of values

4 If the transition matrix is

\begin{tabular}{l|ll}
\hline & $\theta_{t+1}=\theta^{h}$ & $\theta_{t+1}=\theta^{n}$ \\
\hline$\theta_{t}=\theta^{h}$ & $p_{11}$ & $p_{12}$ \\
$\theta_{t}=\theta^{n}$ & $p_{21}$ & $p_{22}$ \\
\hline
\end{tabular}

The unconditional probability of being in state 1 (i.e., $\theta_{t}=\theta^{h}$ ) at any given date will be given by

$$
P\left(\theta_{t}=\theta^{h}\right)=\frac{1-p_{22}}{2-p_{11}-p_{22}}=0.5
$$

and the unconditional probability of being in state $2\left(\theta_{t}=\theta^{n}\right)$ is:

$$
P\left(\theta_{t}=\theta^{n}\right)=1-P\left(\theta_{t}=\theta^{h}\right)=0.5
$$

Then, the unconditional mean of $\theta$ is:

$$
E(\theta)=0.5\left(\theta^{h}+\theta^{n}\right)=1
$$




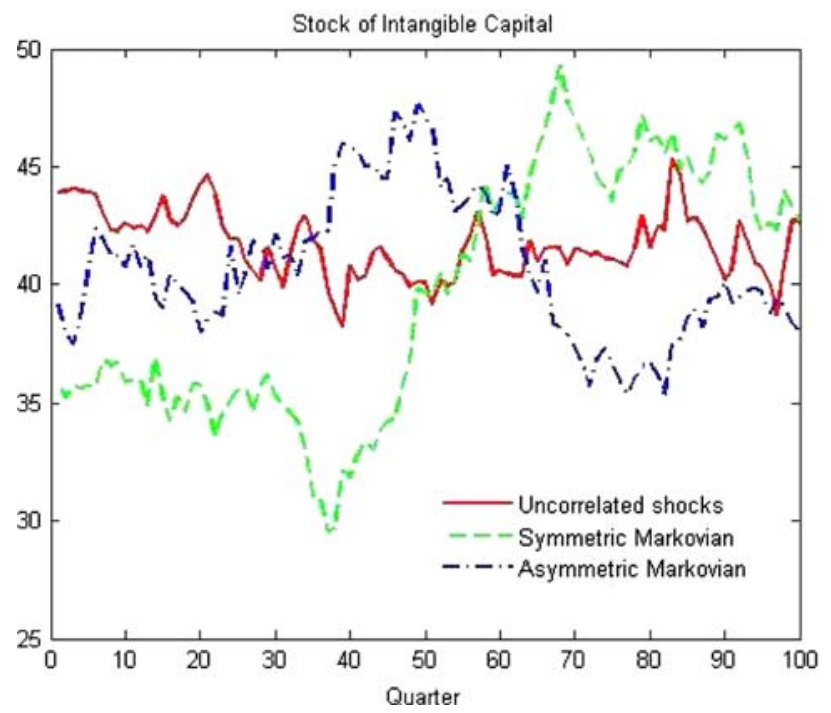

Fig. 1 Three hypotheses for intangible capital

expands to $\pm 25 \%$. Finally, for Scenario 3, we depict a case where the probability of repeating a breakthrough is 0.6 while the persistence coefficient is 0.9 in the no-breakthrough case. The magnitude of a breakthrough is assumed to be 1.4 . The fluctuations in the stock of intangible capital are significantly more modest in this case with $\mathrm{SD}\left(K_{I}\right)=8 \%$ and a range of observed values equal to $\pm 18 \%$.

With dividend taking the form

$$
D_{2, t}=P_{t} Y_{2, t}-I_{2, t}-P_{t} H_{t}-W_{t} L_{2 t},
$$

the 'new economy' firm is assumed to choose a production plan (equivalently, investments in tangible and intangible capital and labor input) to maximize the present value of its expected future dividends, conditional on its current available information:

$$
\max _{\left\{I_{2, t+j}, H_{t+j}, L_{2, t+j}\right\}_{j=0}^{\infty}} E_{t} \sum_{j=0}^{\infty} \rho_{t}^{j} D_{2, t+j}
$$

subject to (2), (5)-(12), one of (9)-(11) and

$$
I_{2, t+j} \geq 0, \quad H_{t+j} \geq 0,1>L_{2, t+j} \geq 0, \quad \forall j \geq 0 .
$$

\section{Equilibrium and solution method}

Our economy is one where markets are effectively complete. As a result, the competitive equilibrium allocation coincides with the solution of a social planner's problem. Our approach to describing the time series properties of this economy will accordingly consist in stating the equivalent social planner's problem, deriving the corresponding FOC's and then log-linearizing the relevant equations around the 
steady state. We will then be in position to numerically compute and characterize the competitive equilibrium allocation.

The social planner chooses optimal consumption and investment policy to enforce a Pareto allocation subject to the social resource constraint. Optimization behavior of firms and our choice of functional forms ensure that the weak inequalities become equalities. Each sector must satisfy its specific resource constraint

$$
\begin{gathered}
C_{1, t}+I_{1, t}+I_{2, t} \leq A_{t} K_{1, t}^{\alpha_{1}} L_{1 t}^{1-\alpha_{1}} \\
C_{2, t}+H_{t} \leq A_{t} K_{I, t}^{\alpha_{I}} K_{2, t}^{\alpha_{2}} L_{2 t}^{1-\alpha_{I}-\alpha_{2}} .
\end{gathered}
$$

The social planner thus solves

$$
\underset{\left\{C_{1, t}, C_{2, t}, K_{1, t}, K_{2, t}, H_{t}, L_{1 t}, L_{2 t}\right\}_{t=0}^{\infty}}{\operatorname{Max}} E_{0} \sum_{t=0}^{\infty} \beta^{t} U\left(C_{1, t}, C_{2, t}, L_{t}\right)
$$

subject to sector resource constraints (13), (14), and the following nonnegativity constraint given $L_{1 t}$ and $L_{2 t}$ :

$$
C_{1, t} \geq 0, C_{2, t} \geq 0, K_{1, t} \geq 0, K_{2, t} \geq 0, K_{I, t} \geq 0,1>L_{1 t} \geq 0,1>L_{2 t} \geq 0
$$

The control variables are $\left\{C_{1, s}, C_{2, s}, K_{1, s}, K_{2, s}, H_{s}, L_{1 s}, L_{2 s} ; s \geq t\right\}$.

The Lagrangian for the social planner's problem is:

$$
\begin{aligned}
\mathcal{L}= & \operatorname{Max}_{\left.\left\{C_{1, t}, C_{2, t}, I_{1, t}, I_{2, t}, H_{t}, L_{1 t}, L_{2 t}\right\}\right|_{t=0} ^{\infty}} E\left\{\sum _ { t = 0 } ^ { \infty } \beta ^ { t } \left[\left(C_{1, t}^{\gamma}+b C_{2, t}^{\gamma}\right)^{1 / \gamma}+\frac{s}{v}\left(1-L_{t}\right)^{v}\right.\right. \\
& -\Lambda_{1, t}\left[C_{1, t}-A_{t} K_{1, t}^{\alpha_{1}} L_{1 t}^{1-\alpha_{1}}+K_{1, t+1}-(1-\delta) K_{1, t}+K_{2, t+1}-(1-\delta) K_{2, t}\right] \\
& \left.\left.-\Lambda_{2, t}\left[C_{2, t}-A_{t} K_{I, t}^{\alpha_{I}} K_{2, t}^{\alpha_{2}} L_{2 t}^{1-\alpha_{I}-\alpha_{2}}+\frac{1}{\theta_{t+1}}\left(K_{I, t+1}-(1-\kappa) K_{I, t}\right)\right]\right]\right\},
\end{aligned}
$$

where $\Lambda_{1, t}, \Lambda_{2, t}$ are Lagrangian multipliers associated with (13) and (14), respectively.

We solve the social planner's problem proceeding in steps. First, we find the first order conditions and constraints; second, we describe the steady state; third, we loglinearise the first-order conditions and constraints around the steady state; fourth, we solve for the recursive equilibrium law of motion. The appendix provides detailed information on the adopted procedure.

\section{Calibration}

As in most of the business cycle literature we calibrate our economy with the view that the steady state values of the major aggregates and ratios should conform to secular observations for the US economy. The steady state of our economy is described by the following equations 


$$
\begin{gathered}
\bar{C}_{1}+\delta \bar{K}_{1}+\delta \bar{K}_{2}=\bar{A} \bar{K}_{1}^{\alpha_{1}} \bar{L}_{1}^{1-\alpha_{1}} \\
\bar{C}_{2}+\frac{\kappa \bar{K}_{I}}{\bar{\theta}}=\bar{A} \bar{K}_{I}^{\alpha_{I}} \bar{K}_{2}^{\alpha_{2}}\left(\bar{L}-\bar{L}_{1}\right)^{1-\alpha_{I}-\alpha_{2}} \\
\left(1-\alpha_{1}\right) \bar{K}_{1}^{\alpha_{1}} \bar{L}_{1}^{-\alpha_{1}}=\left(1-\alpha_{I}-\alpha_{2}\right) \bar{K}_{I}^{\alpha_{I}} \bar{K}_{2}^{\alpha_{2}}\left(\bar{L}-\bar{L}_{1}\right)^{-\alpha_{I}-\alpha_{2}} b\left(\frac{\bar{C}_{2}}{\bar{C}_{1}}\right)^{\gamma-1} \\
s(1-\bar{L})^{\nu-1}\left(1-\alpha_{1}\right) \bar{K}_{1}^{\alpha_{1}} \bar{L}_{1}^{-\alpha_{1}}=\left(\bar{C}_{1}^{\gamma}+b \bar{C}_{2}^{\gamma}\right)^{\frac{1}{\gamma}-1} \bar{C}_{1}^{\gamma-1} \\
\frac{1}{\beta}=\bar{A} \alpha_{1} \bar{K}_{1}^{\alpha_{1}-1} \bar{L}_{1}^{1-\alpha_{1}}+(1-\delta) \\
\frac{1}{\beta}=\bar{\theta} \bar{A} \alpha_{I} \bar{K}_{I}^{\alpha_{I}-1} \bar{K}_{2}^{\alpha_{2}}\left(\bar{L}_{-}-\bar{L}_{1}\right)^{1-\alpha_{I}-\alpha_{2}}+(1-\kappa) \\
\frac{1}{\beta}=(1-\delta)+b\left(\frac{\bar{C}_{2}}{\bar{C}_{1}}\right)^{\gamma-1} \bar{A} \alpha_{2} \bar{K}_{I}^{\alpha_{I}} \bar{K}_{2}^{\alpha_{2}-1}\left(\bar{L}^{-}-\bar{L}_{1}\right)^{1-\alpha_{I}-\alpha_{2}}
\end{gathered}
$$

This system of 7 equations determines the steady state value of 7 endogenous variables $C_{1}, C_{2}, K_{1}, K_{2}, K_{I}, L$, and $L_{1}$ given the values of 10 parameters $b, \gamma, s, v$, $\beta, \delta, \kappa, \alpha_{1}, \alpha_{2}, \alpha_{I}$, and $E(\theta)=1, \bar{A}=1$.

We adopt the usual value for the discount factor $\beta=0.99$ and set the utility curvature parameter at $\gamma=-1$ (we will test other values in the robustness session). We set the parameter $s$ such that the average fraction of hours worked equals $\bar{L}=0.214$ (this requires a values $s=0.128$ in the baseline case). Together with $v=-3$, this value results in a Frisch elasticity of labor supply of 1, as advocated by King and Rebelo (1999). In the traditional sector, the physical capital share parameter is taken to be $\alpha_{1}=0.4$ and the quarterly depreciation rate for physical capital in both sectors is set at $\delta=0.02$.

The values of the remaining parameters concerning the "new economy" sector are then set as follows: $b=0.2, \kappa=0.025$, and in the baseline case, $\alpha_{I}=0.47$ and $\alpha_{2}=0.13$. The parameter $b$ determines the relative price of the two goods. Together with the selected values for the other parameters, our choice of $b$ implies that the traditional good sector is the dominant sector, accounting for $87 \%$ of the steady state GDP in the baseline economy. We will test various values of $b$ in the robustness section. Corrado et al. (2005) estimate an annual depreciation rate for R\&D of about $11 \%$. Our quarterly baseline value is somewhat lower at $2.5 \%$. We examine the impact of alternative hypotheses in our sensitivity analysis.

Table 1 details the main implications of our baseline calibration for the steady state values of various aggregates and ratios. Note that there is an issue of national income accounting here linked with the measurement of intangible capital. We denote $\widehat{\mathrm{GDP}}$ the usual measure of GDP resulting from counting (inappropriately) intangible investment as expenses (hence as an intermediate input) while GDP is the economically correct measure of GDP. We thus have

$$
\widehat{\mathrm{GDP}}=\mathrm{GDP}-H=C_{1}+C_{2}+I_{1}+I_{2} .
$$

Table 1 indicates that for our baseline calibration the true GDP exceeds the mismeasured GDP by 8 percentage points. Besides, the key features of the calibrated economy is that the "new economy sector" accounts for $13 \%$ of GDP and $20 \%$ of 
Table 1 Steady state values and shares - baseline parametrization: $\alpha_{I}=0.47$

\begin{tabular}{lccccccccc}
\hline$\frac{\widehat{G D P}}{\widehat{\mathrm{GDP}}}$ & $\frac{L_{1}}{L}$ & $P$ & $\frac{K_{1}+K_{2}}{\mathrm{GDP}}$ & $\frac{P K_{I}}{\mathrm{GDP}}$ & $\frac{I_{1}+I_{2}}{\mathrm{GDP}}$ & $\frac{P H}{\mathrm{GDP}}$ & $\frac{C_{1}+P C_{2}}{\mathrm{GDP}}$ & $\frac{W L}{\mathrm{GDP}}$ & $\frac{P Y_{2}}{\mathrm{GDP}}$ \\
\hline 1.08 & 0.8 & 0.05 & 2.89 & 0.67 & 0.23 & 0.07 & 0.68 & 0.65 & 0.13 \\
\hline
\end{tabular}

employment, steady state intangible capital amounts to 0.67 GDP while physical capital is 2.89 GDP; total physical investment has a 0.23 share of GDP while intangible investment is 0.7 GDP. We view these numbers as plausible in light both of the standard real business cycle literature and of McGrattan and Prescott (2005) who perform a very detailed and careful examination of the importance of intangible capital. The 0.67 steady state value for intangible investment corresponds to the middle of their estimate for the ratio $K_{I} /$ GDP. In light of Corrado et al. (2005), McGrattan and Prescott (2005) consider lower and upper bounds of 0.5 GDP and 1 GDP. Note that when confronting the stock of capital to the stock market value it is appropriate to restrict oneself to the value added produced by the (publicly traded) corporate sector. With this logic, McGrattan and Prescott (2005) adopt a ratio of physical capital to GDP of about 1 rather than the higher range of 2-3 typically adopted in the real business cycle literature (e.g., Cooley and Prescott 1995). We take the latter as our baseline value (yielding a $\left(K_{1}+K_{2}\right) /$ GDP ratio equal to 2.89 ), thus considering that the totality of intangible capital belongs to the business sector. This interpretation is conservative for our inquiry since it downplays the relative role of intangible capital. It also requires taking with precaution the average value of the stock market to GDP ratio. We will test other parameter values including one producing a value of 1 for the ratio of physical capital to GDP (thus exactly in line with the McGrattan-Prescott calibration). In addition one of our parameter configuration will correspond to a situation where we interpret Sector 2 as the corporate sector (with commensurate physical and intangible capital equal to 1 GDP) and Sector 1 as the non-corporate sector.

Our calibration discussion closes with spelling out the parametrization of the shock processes. We adopt the standard hypotheses for the common aggregate technology shock: the standard deviation of $\varepsilon$ is assumed to be $\sigma_{\varepsilon}=0.007$ and the shock persistence is set at $\psi=0.95$. As to the intangible capital shock process, we retain the values used for Fig. 1, that is, in Scenario 1, the transition matrix is (9) with $p_{s}=0.1$ and $\left(\theta^{h}, \theta^{n}\right)=(1.9,0.9)$; in Scenario 2, the transition matrix is (10) with $p_{s}=0.9$ and $\left(\theta^{h}, \theta^{n}\right)=(1.1,0.9)$; and in Scenario 3, the relevant matrix is (11) and we assume $p_{s}=0.6$ and $\left(\theta^{h}, \theta^{n}\right)=(1.4,0.9)$.

Table 2 summarizes our baseline calibration

Table 2 Parameters in baseline calibration

\begin{tabular}{|c|c|c|c|c|c|c|c|c|c|c|c|c|}
\hline \multicolumn{4}{|c|}{ Preferences } & \multicolumn{4}{|c|}{ Traditional sector } & \multicolumn{5}{|c|}{ "New economy" sector } \\
\hline$\beta$ & $\gamma$ & $s$ & $v$ & $\alpha_{1}$ & $\delta$ & $\sigma_{\varepsilon}$ & $\psi$ & $b$ & $\alpha_{2}$ & $\alpha_{I}$ & $\kappa$ & $\theta$ \\
\hline 0.99 & -1 & 0.128 & -3 & 0.4 & 0.02 & 0.007 & 0.95 & 0.2 & 0.13 & 0.47 & 0.025 & $\left\{\begin{array}{c}\text { Uncorrelated shocks } \\
\text { Symmetric Markovian } \\
\text { Asymmetric Markovian }\end{array}\right.$ \\
\hline
\end{tabular}


Table 3 Main results-quarterly volatility statistics (in percent)

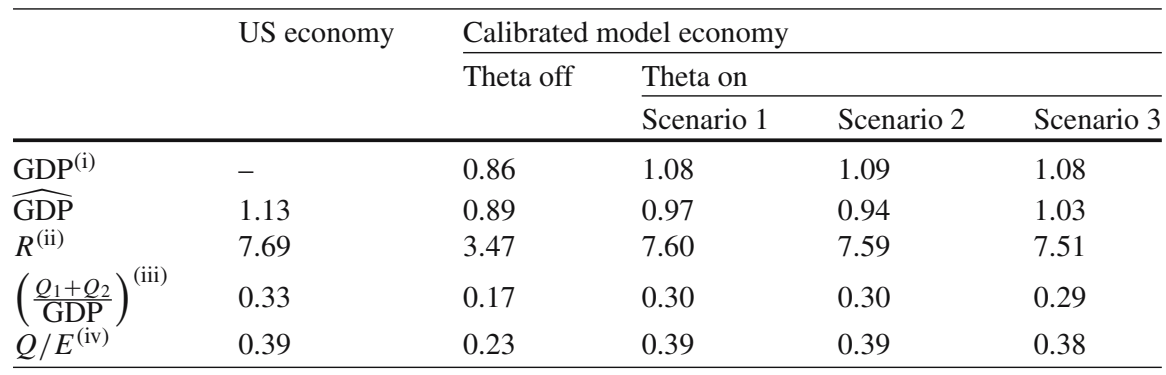

Notes:

- (i) $Y_{1}+P Y_{2} ; \log$ differenced GDP from 1946 Q1 to 2006 Q1.

- (ii) $R$ : rate of return on aggregate market index $\left(Q_{1}+Q_{2}\right)$ inclusive of dividends; $S \& P 500$ index from 1976 Q3 to 2006 Q1.

- (iii) Total market capitalization of NYSE listed stocks/GDP; 1987 Q1 to 2006 Q1; volatility in percent (quarterly volatility relative to its mean).

- (iv) $Q / E$ is the Price to Earnings ratio of the $S \& P 500$ index; 1954 Q1 to 2006 Q1; volatility in percent (quarterly volatility relative to its mean).

- Data source: CEIC

\section{Results}

The main results of our numerical analysis are regrouped in Table 3. The first thing to note is that these results depend very little on the specific hypothesis or scenario adopted for the intangible accumulation process. Despite their very different nature, nothing substantial appears to depend on the fact that one rather than another of our three hypotheses or scenarios turns out to be borne out. What appears crucial, on the other hand, is whether the accumulation process is stochastic rather than deterministic.

At the macroeconomic level, one observes from the first and second lines of Table 3 that the assumption of a stochastic accumulation process for intangible capital does lead to an increase in macroeconomic volatility by about $25 \%$ for our range of parameters. In and of itself, this effect would bring the baseline RBC model closer to reproducing observed GDP volatility, except that the increased macroeconomic volatility remains for a large part unmeasured: the mis-measured GDP volatility increases by $9 \%$ in Scenario 1, as little as $6 \%$ in Scenario 2, and $16 \%$ in Scenario 3. ${ }^{5}$

Turning now to financial indicators, the lesson of our exercise is striking. Assuming a stochastic accumulation process for intangible capital more than doubles the volatility of the stock market return bringing it fully in line with the observations made for the S\&P500 index. Here $R$ stands for the rate of return on the aggregate stock market index inclusive of dividends. It is compared with the rate of return volatility on the S\&P500 measured over the 1946-2006 period. There

\footnotetext{
${ }^{5}$ McGrattan and Prescott (2006) similarly find that, because of the improper measurement of intangible capital, standard accounting measures have understated the boom in productivity and investment in the 1990s.
} 
is no excess volatility puzzle (Shiller 1981) once one entertains the possibility of stochastic intangible capital accumulation!

The volatility of the market capitalization to GDP ratio is doubled as well. Under either of our three scenarios, it closely matches the observations made for the US economy. This is in contrast with Mehra (1998) who argues that the standard model is generically unable to replicate the observed volatility of this ratio. ${ }^{6}$ This result indicates that stochastic capital accumulation generates an increase in financial volatility that is a multiple of the increase in macroeconomic volatility it produces.

Finally we also compute the percent volatility of the Price/Earnings ratio where Earnings $E$ are defined as

$$
E=Y_{1}+P Y_{2}-w L-H-\delta\left(K_{1}+K_{2}\right) .
$$

Table 3 shows the $Q / E$ increasing from a level of 0.23 , when the intangible accumulation process is deterministic, to 0.39 when intangible capital accumulates stochastically, the exact number registered for the S\&P500 over the last 60 years. This confirms the result obtained with the market capitalization to GDP ratio. Stochastic accumulation increases the volatility of corporate valuations substantially more than it increases the volatility of earnings.

As already mentioned it is important to observe that these convincing results do not really depend on the specific assumption made on the stochastic process governing the accumulation of intangible capital. In the next section we show that they are equally robust to alternative calibration assumptions.

\section{Sensitivity analysis}

In this section we perform a broad sensitivity analysis. First we propose parameter configurations designed to obtain various plausible alternative ratios between the stock of intangible capital, the stock of physical capital and GDP. The main tool to achieve this result is the intangible capital share parameter $\alpha_{I}$. We simultaneously adapt the parameter $s$ so as to preserve the labor supply characteristics. The resulting steady state values are reproduced in Table 4. The first two lines make hypotheses on $\alpha_{I}$ that together with appropriate changes in the parameter $s$ generate a physical capital stock to GDP ratio between 2 and 3 (as in the baseline cases) while the stock of intangible capital stands at the two extremes of 0.5 GDP and 1 GDP entertained by McGrattan and Prescott. The next three lines reproduce the main steady state values and ratios when $\alpha_{I}$ and $s$ takes values that produce a physical capital stock to GDP ratio of 1 and three possible values for the stock of intangible capital to GDP ratio (0.5, 0.7 and 1$)$. Table 5 displays the main volatility statistics for the corresponding cases comparing it with the baseline case under Scenario 1 (an hypothesis that is maintained throughout for comparability).

The lesson of Table 5 is one of total uniformity of the financial results delivered by the hypothesis of stochastic intangible accumulation. While the impact

\footnotetext{
6 McGrattan and Prescott (2005) account for the large secular movements in corporate equity values relative to GDP by taking account of the important changes in the US and UK tax and regulatory system, in particular in the effective tax rate on distributions. In a similar vein, Danthine and Donaldson (2002) propose a resolution of the same puzzle postulating that the observed variations in factor income shares constitute an uninsurable risk factor.
} 
Table 4 Sensitivity analysis - alternative values of $\alpha_{I}$ steady state values and shares

\begin{tabular}{|c|c|c|c|c|c|c|c|c|c|c|c|}
\hline$\alpha_{I}$ & $s$ & $\frac{\mathrm{GDP}}{\widehat{\mathrm{GDP}}}$ & $\frac{L_{1}}{L}$ & $P$ & $\frac{K_{1}+K_{2}}{\mathrm{GDP}}$ & $\frac{P K_{I}}{\mathrm{GDP}}$ & $\frac{I_{1}+I_{2}}{\mathrm{GDP}}$ & $\frac{P H}{\mathrm{GDP}}$ & $\frac{C_{1}+P C_{2}}{\mathrm{GDP}}$ & $\frac{W L}{\mathrm{GDP}}$ & $\frac{P Y_{2}}{\mathrm{GDP}}$ \\
\hline 0.52 & 0.086 & 1.11 & 0.81 & 0.08 & 3.00 & 1.00 & 0.24 & 0.10 & 0.65 & 0.61 & 0.17 \\
\hline 0.36 & 0.168 & 1.04 & 0.71 & 0.10 & 2.83 & 0.50 & 0.23 & 0.05 & 0.74 & 0.73 & 0.14 \\
\hline 0.48 & 0.233 & 1.07 & 0.81 & 0.07 & 1.00 & 0.70 & 0.08 & 0.07 & 0.86 & 0.65 & 0.16 \\
\hline 0.53 & 0.179 & 1.10 & 0.86 & 0.06 & 1.00 & 1.00 & 0.08 & 0.10 & 0.82 & 0.59 & 0.18 \\
\hline 0.45 & 0.256 & 1.06 & 0.62 & 0.04 & 1.00 & 0.50 & 0.08 & 0.05 & 0.87 & 0.85 & 0.12 \\
\hline
\end{tabular}

Table 5 Sensitivity analysis - alternative values of $\alpha_{I}$ quarterly volatility statistics (in percent)

\begin{tabular}{|c|c|c|c|c|c|c|c|}
\hline & \multirow[t]{2}{*}{ US Economy } & \multirow[t]{2}{*}{ Baseline } & \multicolumn{5}{|c|}{ Alternative values of $\alpha_{I}$} \\
\hline & & & $\alpha_{I}=0.52$ & $\alpha_{I}=0.36$ & $\alpha_{I}=0.48$ & $\alpha_{I}=0.53$ & $\alpha_{I}=0.45$ \\
\hline GDP & - & 1.08 & 1.22 & 0.94 & 1.09 & 1.28 & 1.02 \\
\hline$\widehat{\mathrm{GDP}}$ & 1.13 & 0.97 & 1.06 & 0.95 & 1.01 & 1.08 & 0.96 \\
\hline$R$ & 7.69 & 7.60 & 7.94 & 7.17 & 7.75 & 7.93 & 7.46 \\
\hline$\left(\frac{Q_{1}+Q_{2}}{\mathrm{GDP}}\right)$ & 0.33 & 0.30 & 0.35 & 0.31 & 0.33 & 0.38 & 0.32 \\
\hline$Q / E$ & 0.39 & 0.39 & 0.42 & 0.35 & 0.40 & 0.44 & 0.40 \\
\hline
\end{tabular}

Notes: See Table 3. Baseline case $=$ stochastic accumulation of intangible capital - Scenario 1

of parameter changes may at times be significant at the macroeconomic level, the financial volatility statistics uniformly deliver an improved perspective relative to an economy with deterministic intangible accumulation: the rate of return volatility never falls under 7\%, the Market capitalization to GDP ratio volatility remains in the interval [0.31-0.38] and the $P / E$ ratio stays in the [0.35-0.44] range.

Table 6 displays the main steady state values and ratios when we modify other parameter values of interest. Here we simply adopt alternative values for the utility curvature parameter $\gamma$, for the parameter determining the relative importance of the two sectors, $b$, and for the depreciation rate of intangible capital, $\kappa{ }^{7}$ The corresponding volatility statistics are reported in Table 7 . The case reported under $b=0.52$ is somewhat special. It aims at depicting a situation where Sector 1 would represent the non-corporate sector of the economy while Sector 2 would be the corporate sector. The parameters are selected so that the steady state stock of physical capital in the corporate sector is about $1 \mathrm{GDP}$, the intangible capital stock is 0.67 GDP, while the overall capital stock is 2.5 GDP. These correspond to the best estimates of McGrattan and Prescott (2005). The spirit of that interpretation is that sector 1 firms are not publicly traded and therefore the stock market capitalization is $Q_{2}$; similarly the stock market return and the Price/Earnings ratio are computed on the basis of Sector 2 data only.

The message of this exercise is once again one of very robust stability of the financial results delivered by the hypothesis of stochastic intangible capital accumulation. Whatever the indicator adopted the volatility measures are significantly more favorable with stochastic accumulation than under the standard hypothesis and this holds true under each and every parameter specifications entertained!

${ }^{7}$ In each case we adapt the parameter $s$ in order to maintain total working time at 0.214 . 
Table 6 Sensitivity analysis - changing other parameters steady state values and shares

\begin{tabular}{|c|c|c|c|c|c|c|c|c|c|c|c|}
\hline & $s$ & $\frac{\mathrm{GDP}}{\widehat{\mathrm{GDP}}}$ & $\frac{L_{1}}{L}$ & $P$ & $\frac{K_{1}+K_{2}}{\mathrm{GDP}}$ & $\frac{P K_{I}}{\mathrm{GDP}}$ & $\frac{I_{1}+I_{2}}{\mathrm{GDP}}$ & $\frac{P H}{\mathrm{GDP}}$ & $\frac{C_{1}+P C_{2}}{\mathrm{GDP}}$ & $\frac{W L}{\mathrm{GDP}}$ & $\frac{P Y_{2}}{\mathrm{GDP}}$ \\
\hline$\gamma=0$ & 0.132 & 1.09 & 0.81 & 0.10 & 2.68 & 0.75 & 0.21 & 0.08 & 0.69 & 0.60 & 0.19 \\
\hline$\gamma=-2$ & 0.085 & 1.07 & 0.81 & 0.03 & 2.88 & 0.46 & 0.23 & 0.05 & 0.69 & 0.68 & 0.08 \\
\hline$b=0.33$ & 0.097 & 1.11 & 0.81 & 0.09 & 2.68 & 0.99 & 0.21 & 0.10 & 0.68 & 0.59 & 0.20 \\
\hline$b=0.5$ & 0.093 & 1.10 & 0.81 & 0.14 & 2.55 & 0.94 & 0.20 & 0.09 & 0.70 & 0.58 & 0.24 \\
\hline$b=0.52$ & 0.088 & 1.06 & 0.81 & 0.20 & 2.54 & 0.67 & 0.20 & 0.07 & 0.73 & 0.57 & 0.24 \\
\hline$\kappa=0.02$ & 0.116 & 1.04 & 0.81 & 0.04 & 2.88 & 0.66 & 0.23 & 0.07 & 0.72 & 0.68 & 0.11 \\
\hline$\kappa=0.03$ & 0.133 & 1.10 & 0.81 & 0.08 & 2.70 & 0.72 & 0.22 & 0.07 & 0.70 & 0.63 & 0.17 \\
\hline
\end{tabular}

Table 7 Sensitivity analysis - changing other parameters quarterly volatility statistics (in percent)

\begin{tabular}{|c|c|c|c|c|c|c|c|c|c|c|}
\hline & \multirow[t]{3}{*}{ US } & \multirow[t]{3}{*}{ Baseline } & \multicolumn{8}{|c|}{ Alternatives } \\
\hline & & & \multicolumn{2}{|l|}{$\gamma$} & \multicolumn{3}{|l|}{$b$} & \multicolumn{2}{|l|}{$\kappa$} & $\frac{(K 1+K 2)}{G D P}$ \\
\hline & & & 0 & -2 & 0.33 & 0.5 & 0.52 & 0.02 & 0.03 & 1 \\
\hline GDP & - & 1.08 & 1.18 & 1.01 & 1.09 & 1.16 & 1.23 & 1.03 & 1.14 & 0.85 \\
\hline$\widehat{\text { GDP }}$ & 1.13 & 0.97 & 1.05 & 1.01 & 0.99 & 1.08 & 1.11 & 1.02 & 1.10 & 0.67 \\
\hline$R$ & 7.69 & 7.60 & 7.83 & 7.27 & 7.71 & 7.92 & $8.47^{(i)}$ & 7.52 & 7.77 & 6.38 \\
\hline$\left(\frac{Q_{1}+Q_{2}}{\mathrm{GDP}}\right)$ & 0.33 & 0.30 & 0.32 & 0.27 & 0.31 & 0.33 & $0.39^{(i)}$ & 0.28 & 0.34 & 0.25 \\
\hline$Q / E$ & 0.39 & 0.39 & 0.40 & 0.38 & 0.40 & 0.40 & $0.49^{(i)}$ & 0.37 & 0.40 & 0.33 \\
\hline
\end{tabular}

Notes: See Table 3. Baseline case $=$ stochastic accumulation of intangible capital - Scenario 1 .

(i) Based on $Q_{2}$ rather than $Q_{1}+Q_{2}$

\section{Conclusion}

There is growing evidence that unmeasured intangible investment is large and variable and that proper measurement and accounting of intangible capital may be necessary to explain important and puzzling observations. In this paper we have argued that the recent strand of literature emphasizing the role of intangible investment should be extended to question the process by which intangible capital is accumulated. Specifically we have observed that, along important dimensions, the properties of an artificial economy where intangible investment translates into capital according to a stochastic process, close to the one used to describe the result of R\&D investment, differ significantly from those if intangible and physical capital are assumed to accumulate in the same way.

We make our case within a two-sector general equilibrium model with the defining characteristics that the "new economy' sector crucially requires intangible capital for production. If the law of motion of intangible capital is deterministic, our model is fully standard and faces the typical inability of DSGE models in accounting for the observed properties of equity returns as documented by, e.g., Rouwenhorst (1995). Jermann (1998) and Boldrin et al. (2001), among many others, have proposed possible solutions involving habit formation (as suggested by exchange economies studies) coupled with strong rigidities - fixed labor supply coupled with capital adjustment costs in Jermann, restrictions to inter-sectoral labor flows in Boldrin et al. - preventing the high marginal risk aversion of the agents 
to translate into counter-factual real decisions and behavior. See Danthine et al. (2006) for a more complete account.

Here, following a very different route, we have shown that, under a plausible parametrization, moving from a deterministic to a stochastic accumulation process for intangible capital leads to an increase of measured GDP volatility of $6 \%$, an increase in stock return volatility of $120 \%$, of the volatility of the market capitalization to GDP ratio of $76 \%$ and an increase of the Price to Earnings ratio volatility of $70 \%$. The assumption of a stochastic accumulation process for intangible capital is thus revealed to be crucially important for the properties of stock returns, corporate valuation and price to earnings ratio. Our results are robust to the details of the stochastic process governing intangible capital accumulation as well as to alternative hypotheses on the calibration of our economy.

We are thus led to the conclusion that the hypothesis of stochastic intangible accumulation could be instrumental in resolving outstanding financial volatility puzzles and accounting for the observed volatility of stock prices and returns and corporate valuation. Our inquiry is definitely exploratory in nature. We view our main contribution as underlining the interest of accumulating new evidence on intangible capital beyond measures of intangible investments.

\section{Appendix: solution method}

Constraints and first-order conditions

See Sect. 3.

Let us start with a change of notation and denote current capital stock $K_{i, t-1}$, $i=1,2, I$, where $t-1$ then refers to the fact that it results from decision made in $t-1$. The Lagrangian then becomes:

$$
\begin{aligned}
\mathcal{L}= & \operatorname{Max}_{\left.\left\{C_{1, t}, C_{2, t}, I_{1, t}, I_{2, t}, H_{t}, L_{t}, L_{1 t}\right\}\right|_{t=0} ^{\infty}} E\left\{\sum _ { t = 0 } ^ { \infty } \beta ^ { t } \left[\left(C_{1, t}^{\gamma}+b C_{2, t}^{\gamma}\right)^{1 / \gamma}+\frac{s}{v}\left(1-L_{t}\right)^{v}\right.\right. \\
& -\Lambda_{1, t}\left[C_{1, t}-A_{t} K_{1, t-1}^{\alpha_{1}} L_{1 t}^{1-\alpha_{1}}+K_{1, t}-(1-\delta) K_{1, t-1}+K_{2, t}-(1-\delta) K_{2, t-1}\right] \\
& \left.\left.-\Lambda_{2, t}\left[C_{2, t}-A_{t} K_{I, t-1}^{\alpha_{I}} K_{2, t-1}^{\alpha_{2}}\left(L_{t}-L_{1 t}\right)^{1-\alpha_{I}-\alpha_{2}}+H_{t}\right]\right]\right\}
\end{aligned}
$$

The first order conditions are:

$$
\begin{gathered}
\frac{\partial \mathcal{L}}{\partial \Lambda_{1, t}}: C_{1, t}+K_{1, t}-(1-\delta) K_{1, t-1}+K_{2, t}-(1-\delta) K_{2, t-1}-A_{t} K_{1, t-1}^{\alpha_{1}} L_{1 t}^{1-\alpha_{1}}=0 \\
\frac{\partial \mathcal{L}}{\partial \Lambda_{2, t}}: C_{2, t}+H_{t}-A_{t} K_{I, t-1}^{\alpha_{I}} K_{2, t-1}^{\alpha_{2}}\left(L_{t}-L_{1 t}\right)^{1-\alpha_{I}-\alpha_{2}}=0 \\
\frac{\partial \mathcal{L}}{\partial C_{1, t}}:\left(C_{1, t}^{\gamma}+b C_{2, t}^{\gamma}\right)^{\frac{1}{\gamma}-1} C_{1, t}^{\gamma-1}=\Lambda_{1, t} \\
\frac{\partial \mathcal{L}}{\partial C_{2, t}}:\left(C_{1, t}^{\gamma}+b C_{2, t}^{\gamma}\right)^{\frac{1}{\gamma}-1} b C_{2, t}^{\gamma-1}=\Lambda_{2, t}
\end{gathered}
$$




$$
\begin{gathered}
\frac{\partial \mathcal{L}}{\partial L_{1, t}}, \frac{\partial \mathcal{L}}{\partial L_{2, t}}:\left(1-\alpha_{1}\right) K_{1 t}^{\alpha_{1}} L_{1 t}^{-\alpha_{1}}=\left(1-\alpha_{I}-\alpha_{2}\right) K_{I t}^{\alpha_{I}} K_{2 t}^{\alpha_{2}}\left(L_{t}-L_{1 t}\right)^{-\alpha_{I}-\alpha_{2}} P_{t} \\
s\left(1-L_{t}\right)^{\nu-1}\left(1-\alpha_{1}\right) K_{1 t}^{\alpha_{1}} L_{1 t}^{-\alpha_{1}}=\left(C_{1, t}^{\gamma}+b C_{2, t}^{\gamma}\right)^{\frac{1}{\gamma}-1} C_{1, t}^{\gamma-1} \\
\frac{\partial \mathcal{L}}{\partial K_{1, t}}: \Lambda_{1, t}=\beta E_{t}\left\{\Lambda_{1, t+1}\left[A_{t+1} \alpha_{1} K_{1, t}^{\alpha_{1}-1} L_{1 t}^{1-\alpha_{1}}+(1-\delta)\right]\right\} \\
\frac{\partial \mathcal{L}}{\partial K_{2, t}}: \Lambda_{1, t}=\beta E_{t}\left[\Lambda_{1, t+1}(1-\delta)+\Lambda_{2, t+1} A_{t+1} \alpha_{2} K_{I, t}^{\alpha_{I}} K_{2, t}^{\alpha_{2}-1}\left(L_{t}-L_{1 t}\right)^{1-\alpha_{I}-\alpha_{2}}\right] \\
\frac{\partial \mathcal{L}}{\partial K_{I, t}}: \Lambda_{2, t}=\beta E_{t}\left[\Lambda_{2, t+1}\left(A_{t+1} \alpha_{I} K_{I, t}^{\alpha_{I}-1} K_{2, t}^{\alpha_{2}}\left(L_{t}-L_{1 t}\right)^{1-\alpha_{I}-\alpha_{2}} \theta_{t}+\frac{1-\kappa}{\theta_{t+1}} \theta_{t}\right)\right] \\
P_{t}=b\left(\frac{C_{2, t}}{C_{1, t}}\right)^{\gamma-1} \\
\theta_{t} H_{t-1}=K_{I t}-(1-\kappa) K_{I t-1} \\
a_{t}=\psi a_{t-1}+\varepsilon_{t}
\end{gathered}
$$

where $a_{t}=\ln A_{t}$ with $\bar{A}=1 ; \varepsilon_{t} \sim \mathcal{N}\left(0 ; \sigma^{2}\right)$ i.i.d..

Finding the steady state

The steady state of the centralized economy is characterized by:

$$
\begin{gathered}
\bar{C}_{1}+\delta \bar{K}_{1}+\delta \bar{K}_{2}=\bar{A} \bar{K}_{1}^{\alpha_{1}} \bar{L}_{1}^{1-\alpha_{1}} \\
\bar{C}_{2}+\frac{\kappa \bar{K}_{I}}{\bar{\theta}}=\bar{A} \bar{K}_{I}^{\alpha_{I}} \bar{K}_{2}^{\alpha_{2}}\left(\bar{L}-\bar{L}_{1}\right)^{1-\alpha_{I}-\alpha_{2}} \\
\left(1-\alpha_{1}\right) \bar{K}_{1}^{\alpha_{1}} \bar{L}_{1}^{-\alpha_{1}}=\left(1-\alpha_{I}-\alpha_{2}\right) \bar{K}_{I}^{\alpha_{I}} \bar{K}_{2}^{\alpha_{2}}\left(\bar{L}-\bar{L}_{1}\right)^{-\alpha_{I}-\alpha_{2}} b\left(\frac{\bar{C}_{2}}{\bar{C}_{1}}\right)^{\gamma-1} \\
s(1-\bar{L})^{\nu-1}\left(1-\alpha_{1}\right) \bar{K}_{1}^{\alpha_{1}} \bar{L}_{1}^{-\alpha_{1}}=\left(\bar{C}_{1}^{\gamma}+b \bar{C}_{2}^{\gamma}\right)^{\frac{1}{\gamma}-1} \bar{C}_{1}^{\gamma-1} \\
\frac{1}{\beta}=\bar{A} \alpha_{1} \bar{K}_{1}^{\alpha_{1}-1} \bar{L}_{1}^{1-\alpha_{1}}+(1-\delta) \\
\frac{1}{\beta}=\bar{\theta} \bar{A} \alpha_{I} \bar{K}_{I}^{\alpha_{I}-1} \bar{K}_{2}^{\alpha_{2}}\left(\bar{L}_{-}-\bar{L}_{1}\right)^{1-\alpha_{I}-\alpha_{2}}+(1-\kappa) \\
\frac{1}{\beta}=(1-\delta)+b\left(\frac{\bar{C}_{2}}{\bar{C}_{1}}\right)^{\gamma-1} \bar{A} \alpha_{2} \bar{K}_{I}^{\alpha_{I}} \bar{K}_{2}^{\alpha_{2}-1}\left(\bar{L}-\bar{L}_{1}\right)^{1-\alpha_{I}-\alpha_{2}}
\end{gathered}
$$

Log-linearizing the constraints and the first-order conditions

All the following lower case letters denote the log-deviation of their capital letter counterparts.

$$
\begin{aligned}
& \bar{C}_{1} c_{1, t}+\bar{K}_{1} k_{1, t}-(1-\delta) \bar{K}_{1} k_{1, t-1}+\bar{K}_{2} k_{2, t}-(1-\delta) \bar{K}_{2} k_{2, t-1} \\
& =\bar{A}\left(\bar{K}_{1}\right)^{\alpha_{1}} \bar{L}_{1}^{1-\alpha_{1}}\left(a_{t}+\alpha_{1} k_{1, t-1}+\left(1-\alpha_{1}\right) l_{1, t}\right)
\end{aligned}
$$




$$
\begin{aligned}
& \bar{C}_{2} c_{2, t}+\frac{\bar{K}_{I}}{\bar{\theta}}\left(k_{I, t}-(1-\kappa) k_{I, t-1}-\kappa \vartheta_{t}\right) \\
& =\bar{A} \bar{K}_{I}^{\alpha_{I}} \bar{K}_{2}^{\alpha_{2}}\left(\bar{L}-\bar{L}_{1}\right)^{1-\alpha_{I}-\alpha_{2}} \\
& *\left(a_{t}+\alpha_{I} k_{I, t-1}+\alpha_{2} k_{2, t-1}+\left(1-\alpha_{2}-\alpha_{I}\right) l_{2, t}\right) \\
& \left(1-\alpha_{1}\right) \alpha_{1} \bar{K}_{1}^{\alpha_{1}} \bar{L}_{1}^{-\alpha_{1}}\left(k_{1, t}-l_{1, t}\right) \\
& =b\left(1-\alpha_{2}-\alpha_{I}\right) \bar{K}_{I}^{\alpha_{I}} \bar{K}_{2}^{\alpha_{2}}\left(\bar{L}-\bar{L}_{1}\right)^{1-\alpha_{I}-\alpha_{2}}\left(\frac{\bar{C}_{2}}{\bar{C}_{1}}\right)^{\gamma-1}\left[\alpha_{I} k_{I, t}\right. \\
& \left.+\alpha_{2} k_{2, t}-\left(\alpha_{I}+\alpha_{2}\right) l_{2, t}+(\gamma-1)\left(c_{2, t}-c_{1, t}\right)\right] \\
& s(1-\bar{L})^{\nu-1}\left(1-\alpha_{1}\right) \bar{K}_{1}^{\alpha_{1}} \bar{L}_{1}^{-\alpha_{1}} \\
& {\left[\alpha_{1} k_{1 t}-\alpha_{1} l_{1 t}-(v-1)\left(l_{1 t}+l_{2 t}\right)\right]} \\
& =\left(\bar{C}_{1}^{\gamma}+b \bar{C}_{2}^{\gamma}\right)^{\frac{1}{\gamma}-1} \bar{C}_{1}^{\gamma-1} b(1-\gamma) c_{2 t} \\
& 0=E_{t}\left[\bar{A} \alpha_{1} \bar{K}_{1}^{\alpha_{1}-1} \bar{L}_{1}^{1-\alpha_{1}}\left(a_{t+1}+\left(\alpha_{1}-1\right) k_{1, t}+\left(1-\alpha_{1}\right) l_{1, t}\right)\right] \\
& E_{t}\left[\begin{array}{c}
\bar{\theta} \bar{A} \alpha_{I} \bar{K}_{I}^{\alpha_{I}-1} \bar{K}_{2}^{\alpha_{2}}\left(\bar{L}-\bar{L}_{1}\right)^{1-\alpha_{I}-\alpha_{2}}\left[a_{t+1}\right. \\
+\left(\alpha_{I}-1\right) k_{I, t}+\alpha_{2} k_{2, t}+\vartheta_{t}+ \\
\left.\left(1-\alpha_{2}-\alpha_{I}\right) l_{2, t}\right]+(1-\kappa)\left[\vartheta_{t}-\vartheta_{t+1}\right]
\end{array}\right]=0 \\
& E_{t}\left[\begin{array}{c}
b\left(\frac{\bar{C}_{2}}{\bar{C}_{1}}\right)^{\gamma-1} \bar{A} \alpha_{2} \bar{K}_{I}^{\alpha_{I}} \bar{K}_{2}^{\alpha_{2}-1}\left(\bar{L}-\bar{L}_{1}\right)^{1-\alpha_{I}-\alpha_{2}} \\
*\left[a_{t}+(\gamma-1)\left(c_{2 t}-c_{1 t}\right)+\alpha_{I} k_{I, t}\right. \\
\left.+\left(\alpha_{2}-1\right) k_{2, t}+\left(1-\alpha_{2}-\alpha_{I}\right) l_{2, t}\right]
\end{array}\right]=0 \\
& a_{t}=\psi a_{t-1}+\varepsilon_{t} \\
& C_{1 t}, C_{2 t}, K_{1 t}, K_{2 t}, K_{I t}, H_{t} \geq 0,1>L_{1 t}, L_{2 t} \geq 0 \forall t
\end{aligned}
$$

Thus, we have 7 equations [from (23) to (29)] and 7 unknowns $c_{1 t}, c_{2 t}, k_{1 t}, k_{2 t}$, $k_{I t}, l_{1 t}, l_{2 t}$, plus two shocks' description $a_{t}$ and $\theta_{t}$.

Solving for the recursive equilibrium law of motion

We solve for the recursive equilibrium law of motion via the method of undetermined coefficients. The idea is to write all variables as linear functions (the "recursive equilibrium law of motion") of a vector of endogenous variables and exogenous variables which are given at date $t$. These are the state and the predetermined variables.

We denote:

$$
x_{t}=\left(\begin{array}{l}
k_{1, t} \\
k_{2, t} \\
k_{I, t} \\
l_{1, t} \\
l_{2, t}
\end{array}\right), \quad \text { endogenous state variables; }
$$




$$
\begin{aligned}
& y_{t}=\left(\begin{array}{l}
c_{1, t} \\
c_{2, t}
\end{array}\right), \quad \text { other endogenous variables; } \\
& z_{t}=\left(\begin{array}{c}
a_{t} \\
\vartheta_{t}
\end{array}\right), \quad \text { exogenous stochastic variables. }
\end{aligned}
$$

What one is looking for is the recursive equilibrium law of motion

$$
\begin{aligned}
& x_{t}=\mathrm{PP} x_{t-1}+\mathrm{QQ} z_{t} \\
& y_{t}=\mathrm{RR} x_{t-1}+\mathrm{SS} z_{t}
\end{aligned}
$$

i.e., matrices PP, QQ, RR and SS such that the equilibrium described by these rules is stable.

It is assumed that the log-linearized equilibrium relationships can be written in the form:

$$
\begin{aligned}
0 & =\mathrm{AA} x_{t}+\mathrm{BB} x_{t-1}+\mathrm{CC} y_{t}+\mathrm{DD} z_{t} \\
0 & =E_{t}\left[\mathrm{FF} x_{t+1}+\mathrm{GG} x_{t}+\mathrm{HH} x_{t-1}+\mathrm{JJ} y_{t+1}+\mathrm{KK} y_{t}+\mathrm{LL} z_{t+1}+\mathrm{MM} z_{t}\right] \\
z_{t+1} & =\mathrm{NN} z_{t}+\varepsilon_{t+1} ; E_{t}\left[\varepsilon_{t+1}\right]=0 .
\end{aligned}
$$

The matrices for system (30) can be obtained from Eqs. (23) to (29) with:

$\varepsilon_{t+1} \sim \mathcal{N}\left(0, \sigma^{2}\right)$ i.i.d.

$\theta_{t}$ specified according to the relevant scenario;

$C_{1 t}, C_{2 t}, K_{1 t}, K_{2 t}, K_{I t} \geq 0,1>L_{1 t}, L_{2 t} \geq 0, \quad \forall t$

or $c_{1 t}, c_{2 t}, k_{1 t}, k_{2 t}, k_{I t}, l_{1 t}, l_{2 t} \geq-1$

The recursive equilibrium laws of motion are obtained in result. Since $x_{t}, y_{t}$ and $z_{t}$ are log-deviations, the entries in PP, QQ, RR, SS can be understood as elasticities and interpreted accordingly.

\section{References}

Boldrin, M., Christiano L., Fisher, J.: Habit persistence, asset returns, and the business cycle. Am Econ Rev 91, 149-166 (2001)

Cooley, T.F., Prescott, E.C.: Economic growth and business cycles. In: Cooley, T.F.: (ed.) Frontiers of Business Cycle Research. Princeton: Princeton University Press (1995)

Corrado, C., Hulten C.R., Sichel D.E.: Measuring capital and technology: an expanded framework. In: Corrado, C., Haltiwanger, J., Sichel, D.: (eds.) Measuring Capital in the New Economy. Chicago: Chicago University Press (2005)

Danthine, J.P., Donaldson, J.B.: Labor relations and asset returns. Rev Econ Stud 69, 41-64 (2002)

Danthine, J.P., Donaldson, J.B., Siconolfi, P.: Distribution risk and equity returns. In: The Equity Risk Premium. Mehra, R.: (ed.) North Holland: North Holland Handbook of Finance Series (2006) (forthcoming)

Hall, R.: e-Capital: The link between the stock market and the labor market in the 1990s. Brookings Pap Econ Act 73-118 (2000)

Hall, R.: The stock market and capital accumulation. Am Econ Rev 91, 1185-1202 (2001)

Jermann, U.: Asset prices in production economies. J Monetary Econ 41, 257-275 (1998)

King, R., Rebelo, S.: Resuscitating real business cycles. Chapter 14. In: Taylor, J., Woodford, M.: (eds.) Handbook of Macroeconomics, vol 1, North Holland: Elsevier (1999) 
Laitner, J., Stolyarov, D.: Technological change and the stock market. Am Econ Rev 93, 1240$1267(2003)$

McGrattan, E.R., Prescott, E.C.: Taxes, Regulations, and the value of U.S. and U.K. corporations. Rev Econ Stud 72, 767-796 (2005)

McGrattan, E.R., Prescott, E.C.: Unmeasured investment and the 1990s U.S. hours boom, research Department Staff Report 369, Federal Reserve Bank of Minneapolis (2006)

Mehra, R., Prescott, E.C.: The equity premium: A puzzle. J Monetary Econ 22, 145-161 (1985)

Mehra, R.: On the volatility of stock prices: an exercise in quantitative Theory. Int J Syst Sci 29, 1203-1211 (1998)

Rouwenhorst, K.G.: Asset pricing implications of equilibrium business cycle models. In: Cooley, T.F.: (ed.) Frontiers of Business Cycle Research. Princeton: Princeton University Press (1995)

Shiller R.: Do stock prices move too much to be justified by subsequent changes in dividends?. Am Econ Rev 71, 421-436 (1981)

Zambon, S.: Study on the measurement of intangible assets and the associated reporting practices (2003) 